\title{
Advanced numerical modelling of tsunami wave propagation, transformation and run-up
}

\section{Aggelos S. DIMAKOPOULOS ${ }^{1}$, Antonella GUERCIO², Giovanni CUOMO ${ }^{1}$}

HR Wallingford Ltd, Howbery Park, Wallingford, Oxfordshire OX10 8BA, UK

2 URS - Consulting Engineering, Basingstoke, Hampshire, UK

Proceedings of the Institution of Civil Engineers Engineering and Computational Mechanics 167, (3),

September 2014

\section{Abstract}

This paper presents a series of numerical models tests performed to assess the ability of the OpenFOAM ${ }^{\circledR}$ modelling system to represent the physics that stands behind the propagation of tsunami waves in coastal regions and in particular their transformation (by means of shoaling, refraction, reflection) over uneven bathymetries and their interaction with the shoreline (run-up, run-down, breaking). A series of tests is selected from the literature to explore the accuracy, applicability and limitations of this particular computational fluid dynamics model solving the threedimensional Navier-Stokes equations for incompressible multiphase fluids. The range of scenarios tested includes experimental work on wave propagation over shoals, solitary wave run-up and the Monai valley tsunami physical model test recreating the Hokkaido-Nansei-Oki 1993 tsunami that struck Okushiri Island, Japan. This allowed direct comparison with experimental data from physical model tests as well as with other established two-dimensional - that is, depth integrated - and three-dimensional numerical models.

\section{Notation}

$\begin{array}{llll}a & \text { volume fraction over a vertical column } & T & \text { wave period } \\ C_{s} & \text { Smagorinsky coefficient } & t & \text { time } \\ d & \text { water depth } & t^{\star} & \text { non-dimesional time } \\ e & \text { relative difference from experimental data } & u_{i} & \text { Cartesian components of the velocity } \\ g & \text { acceleration due to gravity } & u_{n} & \text { normal velocity vector } \\ H & \text { wave height } & u_{t} & \text { tangential velocity vector } \\ H_{\text {exp }} & \text { experimentally predicted wave height } & x_{i} & \text { Cartesian coordinates } \\ H_{i} & \text { average incident wave height } & \alpha & \text { water volume fraction } \\ H_{\text {num }} & \text { numerically predicted wave height } & \tan \beta & \text { beach slope }\end{array}$


$H_{0} \quad$ nominal wave height

i coordinate or component index

j coordinate or component index (Einstein notation)

$N \quad$ number of wave probes

$n \quad$ unit normal vector

$P_{\text {atm }} \quad$ atmospheric pressure

$p \quad$ pressure

$R_{2} \quad$ correlation coefficient

$r \quad$ growth ratio
$\Delta x_{1} \quad$ cell size at main propagation direction in horizontal plane

$\Delta x_{2} \quad$ cell size along vertical (gravity) direction

$\Delta x_{3} \quad$ cell size normal to main propagation direction in horizontal plane

$\eta \quad$ free-surface elevation

$\lambda \quad$ wavelength

$\mu \quad$ dynamic molecular viscosity

$\rho \quad$ density

$\sigma_{r} \quad$ relaxation coefficient

$T_{i j} \quad$ turbulent stress tensor

\section{Introduction}

Until recently, two-dimensional (2D) depth-integrated numerical models, solving mild slope (Berkhoff, 1982), shallow water (Saint Venant, 1871) or Boussinesq (Boussinesq, 1872) equations were generally used to support engineering applications with respect to wave transformation over uneven bathymetries and interaction with coastal structures (Galland et al., 1991; Wei and Kirby, 1995), while the use of threedimensional (3D) Navier-Stokes models was usually restricted to research studies (Christensen, 2006; Watanabe et al., 2005). After decades of development, 2D depth-integrated models are fast, relatively accurate and reliable; however, their accuracy in predicting wave breaking, run-up and wave loading is limited, owing to the fact that they use simplifying assumptions to describe the variation of the flow along the depth in the surf and the swash zone and they do not simulate the air phase, which is critical for the accurate prediction of plunging breaking, wave overtopping and wave loading.

With the progress in computer technology, the computational cost associated with performing and postprocessing 3D simulations has become affordable for engineering-related problems. In addition, the development of open-source computational fluid dynamics (CFD) software with advanced meshing and computational capabilities, such as OpenFOAM ${ }^{\circledR}$ has promoted the use of fully 3D CFD models for engineering applications. Two-phase (air/water) 3D CFD models present several advantages in modelling coastal flows, as they are capable of simulating the complex free-surface dynamics pertaining to wave transformation in the surf and the swash zone, without requiring complex boundary conditions for modelling free-surface overturning, air entrainment and shoreline motion. Examples of modelling the two-phase, 3D nearshore flow induced by wave propagation and interaction with bathymetries and structures are presented, among others, in the works of Hsiao and Lin (2010) and Higuera et al. (2013).

In this paper, an OpenFOAM ${ }^{\circledR}$-based numerical model is presented for applications in coastal engineering. The model uses the relaxation zone method for wave generation and absorption (Jacobsen et al., 2012; Mayer et al., 1998) and it is developed, validated and optimised for coastal and hydraulic engineering applications ( HR Wallingford, 2013). In the current paper, part of this work is presented; the model is validated against some of the most classical benchmark test cases for the validation of numerical models for use in simulation of the dynamics of water waves, namely two cases of regular and solitary wave propagation (Berkhoff, 1982; Briggs et al., 1995; Ito and Tanimoto, 1972; Synolakis, 1986). It is also 
demonstrated that the model is capable of generating and absorbing a tsunami from experimental or field surface elevation measurements, by simulating the benchmark case of Monai valley (Liu et al., 2008).

\section{Numerical model}

The numerical model presented here is based on the OpenFOAM ${ }^{\circledR}$ open source modelling system (OpenFOAM ${ }^{\circledR}$ Foundation, 2013). The software development is sponsored by ESI-OpenCFD and released under the GNU general public license (version 3). OpenFOAM ${ }^{\circledR}$ comes with a built-in set of software libraries that enable it to simulate a variety of CFD cases. In this work, the software is used to numerically solve the $3 \mathrm{D}$, incompressible, immiscible, two-phase flow induced by wave propagation, transformation, breaking and run-up.

\subsection{Model formulation}

The model solves the 3D Navier-Stokes equations for two-phase incompressible motion. The mass and momentum conservation equations in differential form are shown in Equations 1 and 2, respectively.

$\frac{\partial \rho u_{1}}{\partial t}+\frac{\partial \rho u_{j} u_{1}}{\partial x_{i}}=-\frac{\partial p}{\partial x_{i}}+\frac{\partial}{\partial x_{j}}\left(\mu \frac{\partial u_{i}}{\partial x_{j}}\right)+\frac{\partial \mathrm{T}_{i j}}{\partial x_{j}}$

$\frac{\partial u_{j}}{\partial x_{j}}=0$

where $t$ is the time, $x_{i}$ are the Cartesian coordinates, $u_{i}$ are the velocity components, $r$ is the density, $\mu$ is the dynamic molecular viscosity, $\mathrm{p}$ is the pressure and $\mathrm{T}_{\mathrm{ij}}$ is the turbulent stress tensor.

The stress tensor $\mathrm{T}_{\mathrm{ij}}$ is defined according to the modelling approach for the turbulence. In this work, the large eddy simulation (LES) method is applied, where wave breaking is expected to occur. According to this method, turbulence is decomposed to large- and small-scale structures. Large-scale structures are directly resolved by the numerical solution of Equations 1 and 2, whereas small-scale effects are accounted for by a sub-grid scale (SGS) stress model. SGS stresses denote the transfer of momentum from large-scale to small-scale structures. The LES method and SGS stress models have been widely discussed in the literature; interested readers might refer, among others, to the work of Pope (2000).

The free surface is simulated as an air-water interface and its motion is defined by Equation 3, according to the volume of fluid (VOF) method (Hirt and Nichols, 1981).

$\frac{\partial a}{\partial t}+u_{j} \frac{\partial a}{\partial x_{j}}=0$

The volume fraction of water $\alpha$ varies from 1 (100\% water) to 0 (100\% air) and it is related to the density and the molecular viscosity according to Equation 4.

$(\mu, \rho)=\alpha \cdot\left(\mu_{w}, \rho_{w}\right)+(1-\alpha) \cdot\left(\rho_{a}, \mu_{a}\right)$

where subscripts ' $w$ ' and 'a' denote the water and the air phases, respectively. The values of $\rho$ and $\mu$ for each phase considered here are: $\rho_{\mathrm{w}}=1000 \mathrm{~kg} / \mathrm{m}^{3}, \rho_{\mathrm{a}}=1 \mathrm{~kg} / \mathrm{m}^{3}, \mu_{\mathrm{w}}=0.001 \mathrm{~Pa} \mathrm{~s}$ and $\mu_{\mathrm{s}}=0.015 \mathrm{~Pa} \mathrm{~s}$. In this work, no account is made of surface tension effects.

The discretisation of Equations 1-3 is achieved through the finite-volume method. In this context, a mesh is generated and the flow equations are discretised to each internal cell of the mesh, in integral form. Boundary conditions are applied to specific surfaces of the mesh, which have been first characterised as boundary 
patches. More information on various temporal and spatial discretisation schemes used by OpenFOAM ${ }^{\circledR}$ can be found in Jasak (1996). A detailed description of the numerical procedure used to resolve two-phase flows in the software is given in Rusche (2002).

\subsection{Meshing}

The generation of the model mesh is a critical stage of modelling with finite-volume schemes, as the quality of the results is directly dependent on the quality of the mesh. In this work, the built-in tools for OpenFOAM ${ }^{\circledR}$, blockMesh and snappyHexMesh meshing tools are utilised.

The tool blockMesh is elementary for generating simple structured meshes with hexahedral cells. For engineering applications, a structured mesh is often not capable of reproducing all the geometry features of the problem. In OpenFOAM ${ }^{\circledR}$, an unstructured mesh can be derived from a structured mesh, using the tool snappyHexMesh. The tool can fit a realistic geometry to a structured mesh, first by rearranging shape of the neighbouring cells to follow the geometry and then by removing the part of the mesh which is unnecessary. More information for both meshing tools is available in the software user guide (OpenFOAM ${ }^{\circledR}$ Foundation, 2013).

In this work, one 2D and four 3D meshes are used to simulate the validation cases presented in the next sections. A summary of the properties of these meshes is presented in Table 1, along with typical computational times for parallel execution on 12 central processing unit (CPU) cores. The mesh of the Monai valley case is also presented in Figure 1, as an example of mesh generation with snappyHexMesh.

\subsection{Wave generation and absorption}

Wave generation and absorption are achieved through the relaxation method, originally proposed by Mayer et al. (1998) and first implemented in OpenFOAM ${ }^{\circledR}$ by Jacobsen et al. (2012). The present model uses a version of the relaxation method that is optimised for engineering applications ( HR Wallingford, 2013).

According to the method, the target boundary condition for the velocity and the volume fraction is relaxed to the numerical solution with the utilisation of a weighting average operation. This operation is applied in a domain of the mesh called 'relaxation zone'. The relaxation zone is usually adjacent to boundaries that represent inlets or outlets. The operation is described in Equation 5.

$\left(\alpha, u_{i}\right)=\left(\alpha, u_{i}\right)_{B} \sigma_{r}+\left(\sigma, u_{i}\right)_{N}\left(1-\sigma_{r}\right)$

The value of relaxation coefficient $\sigma_{\mathrm{r}}$ is 1 at the boundary, 0 at the end of the relaxation zone and varies according to an exponential relation (Jacobsen et al., 2012). Indices ' $\mathrm{B}$ ' and ' $\mathrm{N}$ ' denote the calculation of field variables (here $a$ and $u_{i}$ ) from the boundary conditions or the internal flow equations, respectively.

Depending on the purpose of the relaxation zone (generation or absorption of waves), it is named either 'generation/absorption zone' or 'absorption zone'. Wave generation is achieved from known velocity and free-surface elevation profiles. The velocity profile is directly forced in Equation 5 , while the free-surface elevation value is used to define the volume fraction distribution at the boundary ( $a=1$ below the free surface and $a=0$ above). Wave absorption is achieved by forcing zero velocities and a volume fraction distribution that corresponds to the local still water level. 


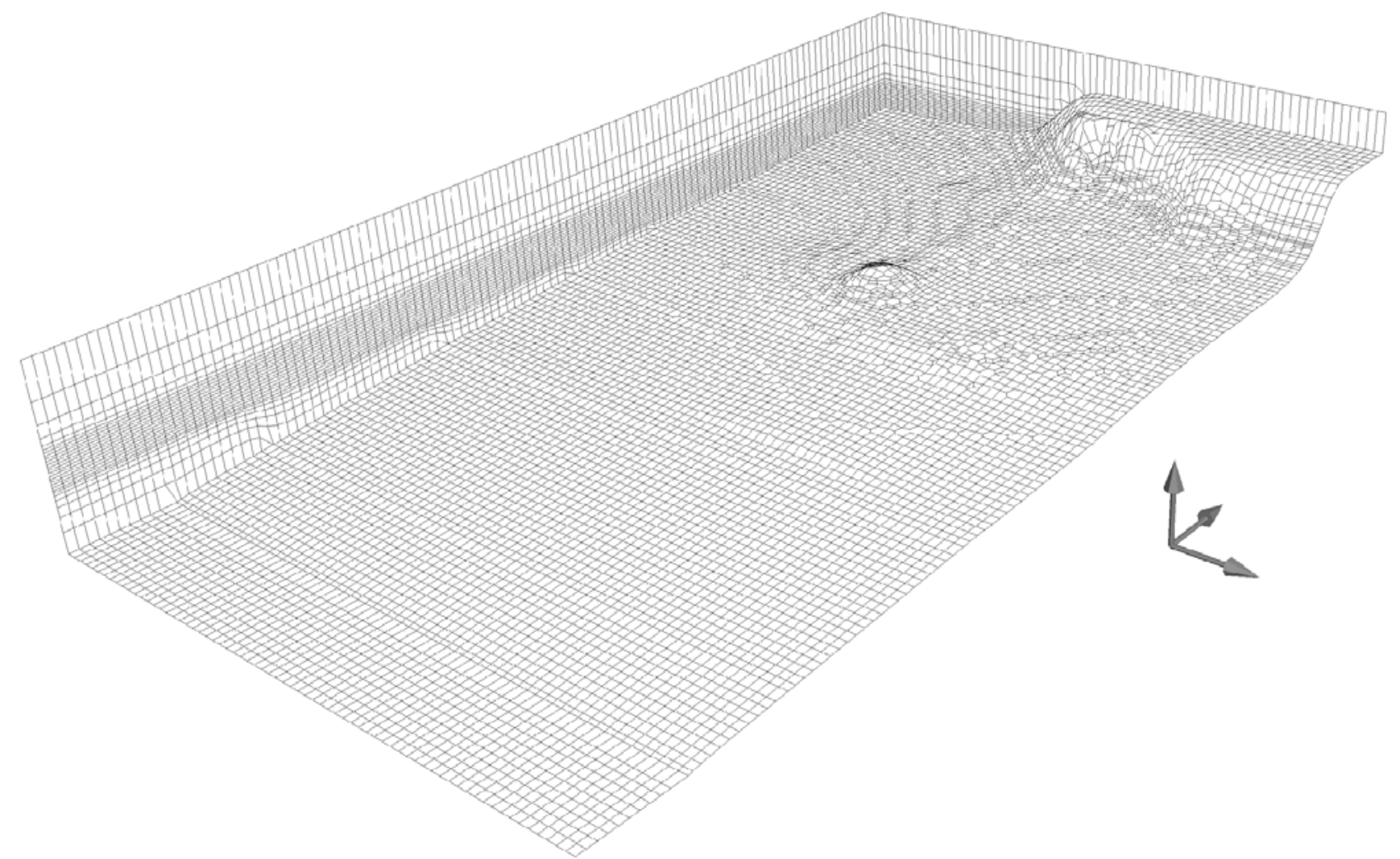

Figure 13 3D mesh used in Monai valley simulation case. For better visualisation, mesh refinement is shown in 2D surfaces (lateral and bottom boundaries)

Table 1 Mesh properties and typical computational times for all simulation cases

\begin{tabular}{|c|c|c|c|c|c|c|}
\hline & $\begin{array}{c}\Delta \mathbf{x}_{1} \\
\text { (horizontal) }\end{array}$ & $\begin{array}{c}\Delta \mathbf{x}_{2} \\
\text { (vertical) }\end{array}$ & $\begin{array}{c}\Delta \mathbf{x}_{3} \\
\text { (horizontal) }\end{array}$ & $\begin{array}{l}\text { Mesh } \\
\text { size: } \\
\text { number } \\
\text { of } \\
\text { cells }\end{array}$ & $\begin{array}{c}\text { Typical } \\
\text { computational } \\
\text { time on } 12 \\
\text { CPU cores: } h\end{array}$ & $\begin{array}{c}\text { Typical } \\
\text { computational } \\
\text { time per } \\
\text { simulation } \\
\text { time on } 12 \mathrm{CPU} \\
\text { cores: } \mathrm{h} / \mathrm{s}\end{array}$ \\
\hline Ito and Tanimoto (1972) shoal & 0.004 & 0.004 & 0.004 & $2 \times 10^{7}$ & $\sim 36$ & $\sim 3.0$ \\
\hline Berkhoff (1982) shoal & 0.014 & $0.018-0.036$ & 0.036 & $1.3 \times 10^{6}$ & $\sim 24$ & $\sim 0.4$ \\
\hline $\begin{array}{l}\text { Two-dimensional solitary wave } \\
\text { run-up (Synolakis, 1986) }\end{array}$ & 0.025 & $0.003-0.025$ & - & $1.8 \times 10^{5}$ & $\sim 2$ & $\sim 0.1$ \\
\hline $\begin{array}{l}\text { Run-up at conical island } \\
\text { (Briggs et al., 1995) }\end{array}$ & 0.04 & $0.005-0.04$ & 0.04 & $6 \times 10^{6}$ & $\sim 24$ & $\sim 1.4$ \\
\hline $\begin{array}{l}\text { Monai valley case (Liu et al., } \\
\text { 2008) }\end{array}$ & 0.052 & 0.005 & 0.05 & $1.7 \times 10^{5}$ & $\sim 4$ & $\sim 0.02$ \\
\hline
\end{tabular}

The relaxation method enables the generation/absorption zone to work as an absorbing numerical wavemaker, leaving the incident wave conditions unaffected by waves reflected in the domain ( HR Wallingford, 2013). The relaxation method is also very efficient in absorbing waves, allowing less than $0.1 \%$ of the wave energy to reflect from the outflow boundary ( HR Wallingford, 2013). 


\subsection{Boundary conditions}

In addition to the relaxation method for wave generation/ absorption, the following boundary conditions are used in the simulations.

- At solid walls, the free-slip boundary condition is used, as defined in Equations 6-8, in terms of pressure, velocity and volume fraction.

$u_{n}=0$

$\frac{\partial p}{\partial n}=0$

$\frac{\partial \alpha}{\partial \boldsymbol{n}}=0$

where $u_{n}$ is the velocity component normal to the boundary and $\boldsymbol{n}$ is the unit normal vector. Equation 5 implies that the boundary layers close to walls are not resolved; this simplification is made to avoid the additional computational cost for resolving the oscillatory boundary layer at the bottom, as it is not significant for wave propagation and shoaling.

- At the atmosphere boundary, the pressure head is equal to the atmospheric pressure, which is set to zero (Equation 9).

$p+\frac{1}{2} u_{j} u_{j}=P_{a t m}=0$

Additionally, an inflow/outflow condition is imposed, by forcing zero gradients conditions for $\mathrm{u}_{\mathrm{j}}$ and $\alpha$, according to Equations 10 and 11, respectively.

$u_{t}=0, \frac{\partial u_{n}}{\partial \boldsymbol{n}}=0$ for $u_{n}<0$ and $\frac{\partial u_{i}}{\partial \boldsymbol{n}}$ for $u_{n}>0$

$\alpha=0$ for $u_{n}<0$ and $\frac{\partial \alpha}{\partial \boldsymbol{n}}=0$ for $u_{n}>0$

where $u_{t}$ is the velocity component tangential to the boundary. The physical meaning of the conditions above is that water and air are allowed to leave the atmosphere boundary, but only air is allowed into the domain, flowing perpendicularly to the boundary.

- At planes where the geometry and the flow are symmetric, a symmetric flow boundary condition is used. For the cases simulated here, this condition works as the free-slip wall (Equations 6-8).

\section{Validation for regular waves}

In this section, the model is validated for 3D wave transformation of regular waves (shoaling and refraction) that propagate over bathymetries with shoals. Two cases that correspond to well known experiments (Berkhoff, 1982; Ito and Tanimoto, 1972) are modelled.

\subsection{Ito and Tanimoto (1972) shoal}

Ito and Tanimoto (1972) studied wave shoaling, refraction and ray intersection over a shoal by performing a physical model. The shoal is a spherical volume with concentric, circular, bathymetry contours, mounted on a flat bottom. In this work, the experiment is numerically reproduced using a 3D flow domain. The bathymetry 
and longitudinal sections of the domain are shown in Ito and Tanimoto (1972). The bathymetry and the wave propagation are symmetric, so half of the domain is considered, with a symmetry plane added at the middle of the domain and parallel to the wave propagation direction.

The operative length of the flow domain is $4.4 \mathrm{~m}$ and the half-width is $1.2 \mathrm{~m}$. The generation/absorption zone and the absorption zone are $0.4 \mathrm{~m}$ and $0.8 \mathrm{~m}$ long respectively, extending at the full width of the domain. Apart from the shoal, the bathymetry is flat, with depth $d=0.15 \mathrm{~m}$. The projection of the shoal to the bottom is a circle, with radius $0.8 \mathrm{~m}$ and the depth at the tip of the shoal is $0.05 \mathrm{~m}$. Surfaces considered as fixed walls (bottom, outlet, side wall opposite to $A A^{\prime}$ ) are assigned to a free-slip boundary condition (Equations 6-8). The atmosphere is modelled according to Equations 9-11. A symmetric flow boundary condition is imposed at the $\mathrm{AA}^{\prime}$ plane. A regular wave condition is generated at the inflow boundary, with nominal wave height $H_{0}=0.0104$, wave period $T=0.51 \mathrm{~s}$ and wavelength $\lambda=0.4 \mathrm{~m}$.

An unstructured mesh is generated, with characteristic cell sizes $\Delta \mathrm{x}_{1}=\Delta \mathrm{x}_{2}=\Delta \mathrm{x}_{3}=0.004 \mathrm{~m}$ at the generation/absorption zone and the bathymetry domain. Cell size $\Delta \mathrm{x}_{1}$ increases in the absorption zone with growth ratio $r=1.1$ : This mesh configuration reduces the computational cost associated with wave absorption by about 90\%, keeping the same efficiency ( HR Wallingford, 2013). The mesh size is about 20 million cells.

The domain is initialised with zero velocity and still water level. The simulation needs about $1.5 \mathrm{~d}$ to run for $12.5 \mathrm{~s}$ of model time, in parallel execution (12 CPU cores, $2.6 \mathrm{GHz}$ each). A 3D snapshot of the free surface at $\mathrm{t} 1 / 410 \mathrm{~s}$ is presented in Figure 2 (top) showing a greyscale map of the free-surface elevation, as the wave propagates over the spherical shoal. The complete domain is reconstructed by mirroring the two symmetric halves. It is observed that the wave amplitude increases and the wave crests are refracted as they propagate above the shoal. The model also predicts the wave ray intersection occurring at the shadow of the shoal, due to wave refraction at both sides, which eventually leads to a short-crested free-surface pattern behind the shoal.

The free-surface elevation is monitored along the cross-sections aa' and bb' (Figure 2(a)), by placing numerical wave probes every $0.1 \mathrm{~m}$. The probes calculate the free-surface elevation by integrating the volume fraction a over a vertical column. The mean zero-crossing wave height is calculated at each location and it is normalised with the average incident wave height $(\mathrm{Hi})$ at the end of the generation/absorption zone.

The numerical predictions at these two sections are compared against physical model data in Figure 2(b). The numerical model is capturing satisfactorily the trend of the distribution and it is very close to the experimental predictions for the wave height values at the central area, at the shadow of the shoal. Away from this central area, there are some discrepancies, possibly because the boundary conditions are not completely representative of the actual experimental configuration. The error is estimated in terms of relative difference from the experimental data using Equation 12.

$e=\frac{1}{n} \sum\left(\frac{H_{n u m}-H_{\text {exp }}}{H_{1}}\right)^{2}$

where $\mathrm{H}_{\text {num }}$ and $\mathrm{H}_{\text {exp }}$ are the numerically and experimentally predicted wave height and $\mathrm{N}$ is the number of wave probes. According to Equation 3, the relative difference is 3\% of $\mathrm{H}_{\mathrm{i}}$. 


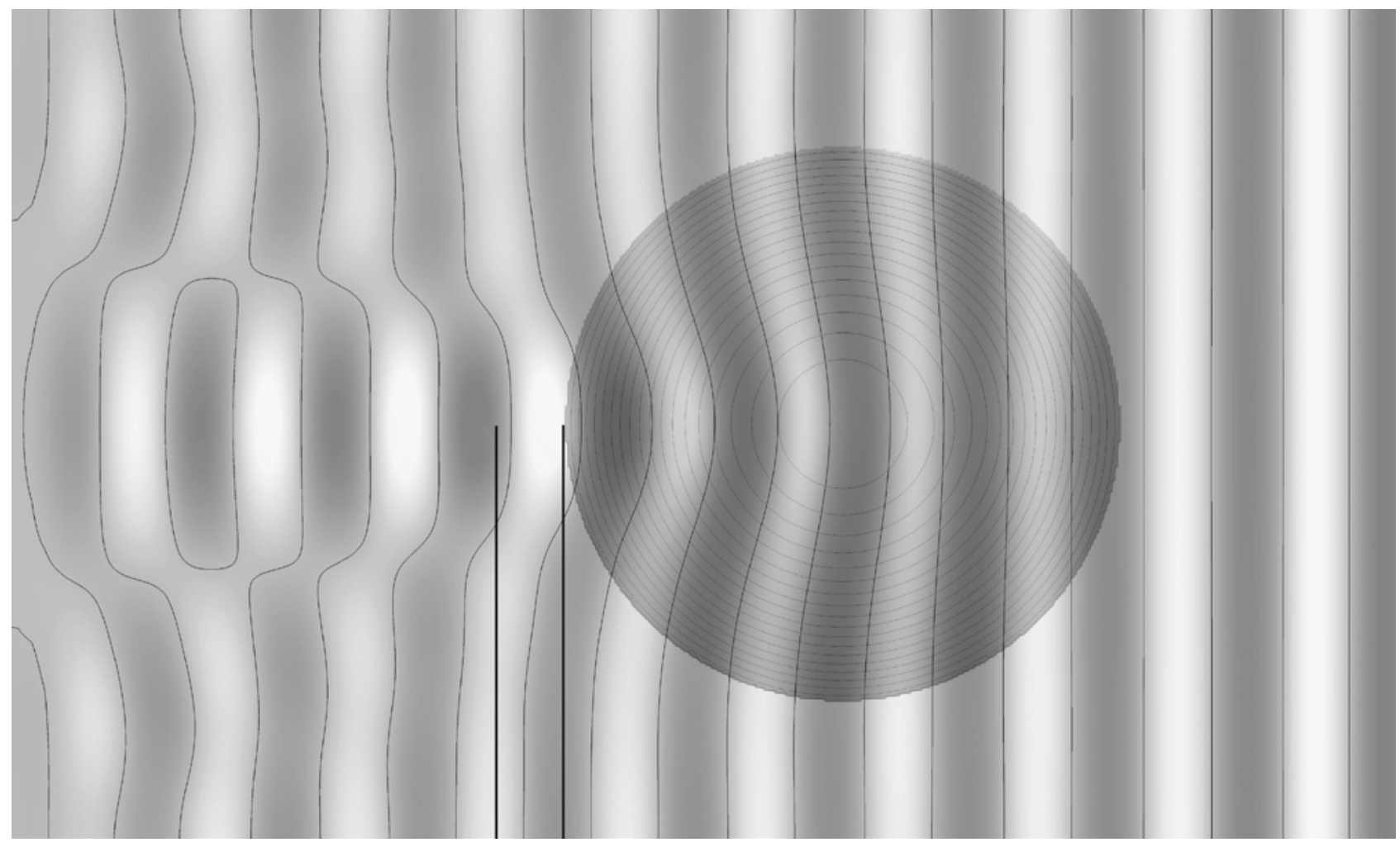

(a)

- Ito and Tanimoto (1972)

Numerical model
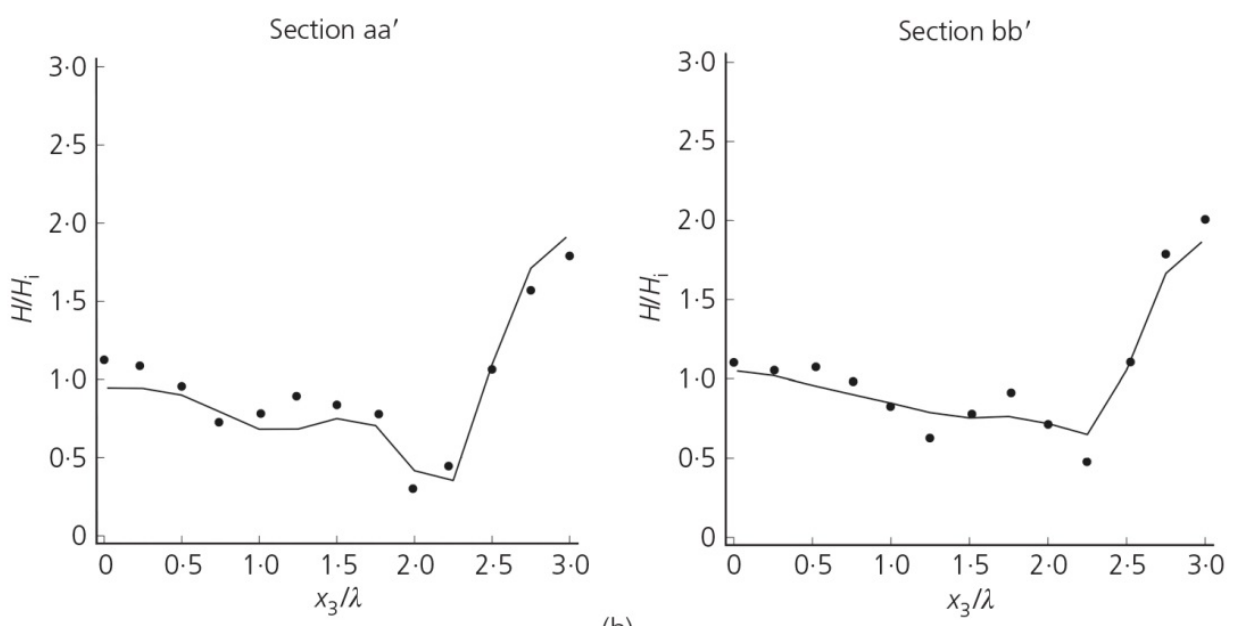

(b)

Figure 2 (a) Free-surface elevation map at t $1 / 49 \mathrm{~s}$. Dark grey corresponds to wave crests, light grey to wave troughs and solid lines to zero free-surface elevation. (b) Wave height distribution at sections aa' and bb', shown in part (a). Symbols correspond to experimental data and solid lines to the numerical model output 


\subsection{Berkhoff (1982) shoal}

A physical model of regular waves propagating over an elliptical shoal, placed on a constant-slope beach, was performed by Berkhoff (1982). The aim of the experiment was to study wave shoaling, refraction and ray intersection, as well as to provide benchmark data for numerical models. The experiment is numerically reproduced using a 3D computational domain. A plan view and a longitudinal section of the bathymetry are shown in Figure 3.

The operative length of the domain is $25 \mathrm{~m}$ and the width is $20 \mathrm{~m}$. The generation/absorption zone and the absorption zone are $1.5 \mathrm{~m}$ and $3 \mathrm{~m}$ long, respectively. The bathymetry consists of a constant-slope beach $(\tan \beta=1 / 50)$ and an elliptical shoal, with major and minor diameters of $4 \mathrm{~m}$ and $3 \mathrm{~m}$, respectively. The centre of the ellipse is located $13 \mathrm{~m}$ from the end of the generation/absorption zone. The slope and the elliptical shoal are rotated $20^{\circ}$ with respect to the wave propagation direction ( $x_{1}$ axis). The water depth at the beginning of the slope is $0.45 \mathrm{~m}$ and $0.125 \mathrm{~m}$ at the tip of the shoal. Wave run-up is not modelled, as it is assumed not to affect wave shoaling and refraction; therefore, the domain was truncated at $0.1 \mathrm{~m}$ and the absorption zone was attached at this depth.

The fixed walls of the domain (bottom, outlet and side walls) are modelled as free-slip walls, according to Equations 6-8. At the atmosphere boundary, the flow is governed by Equations 9-11. A regular wave condition is generated at the inflow boundary, with nominal wave height $H_{0}=0.0232 \mathrm{~m}$, wave period $T=1 \mathrm{~s}$ and wavelength $\lambda=1.5 \mathrm{~m}$.

An unstructured mesh is generated, with characteristic cell sizes $\Delta x_{1}=0.014 \mathrm{~m}$ and $\Delta x_{3}=0.036 \mathrm{~m}$, parallel and normal to the propagation direction, respectively. In the vertical direction, $\Delta x_{2}$ is more refined $(0.018 \mathrm{~m})$ at an area extending $0.03 \mathrm{~m}$ at both sides from the still water level, while $\Delta x_{2}$ is larger outside this area $(0.036 \mathrm{~m})$. The absorption zone mesh is configured similarly to the previous case, to minimise the computational cost. 
The domain is initialised with zero velocities and still water level. The simulation needs about a day to run for $68 \mathrm{~s}$ of model time, in parallel execution ( $12 \mathrm{CPU}$ cores, $2.6 \mathrm{GHz}$ each). A dense grid wave probe is located over and behind the shoal, with spacing $0.1 \mathrm{~m} \times 0.1 \mathrm{~m}$. The grid extends from $5 \mathrm{~m}$ upstream of the shoal, until the bathymetric contour of $0.1 \mathrm{~m}$, occupying the full width of the domain. The mean wave height at every probe location is calculated from the free-surface elevation time series, using zero-crossing analysis.

A map of the wave height in greyscale is presented in Figure 4(a), showing the distribution of the normalised wave height $\left(H / H_{i}\right)$. Behind the shoal, the wave height is increased, reaching about two times the incident wave height and denoting an area of wave focusing. At either side of the wave focusing area, wave height is sharply reduced to almost zero, thus reflecting the existence of two amphidromical points (Berkhoff, 1982). The wave height patterns behind the shoal are not symmetrical with respect to the wave propagation direction, due to the wave crest refraction at the beach slope.

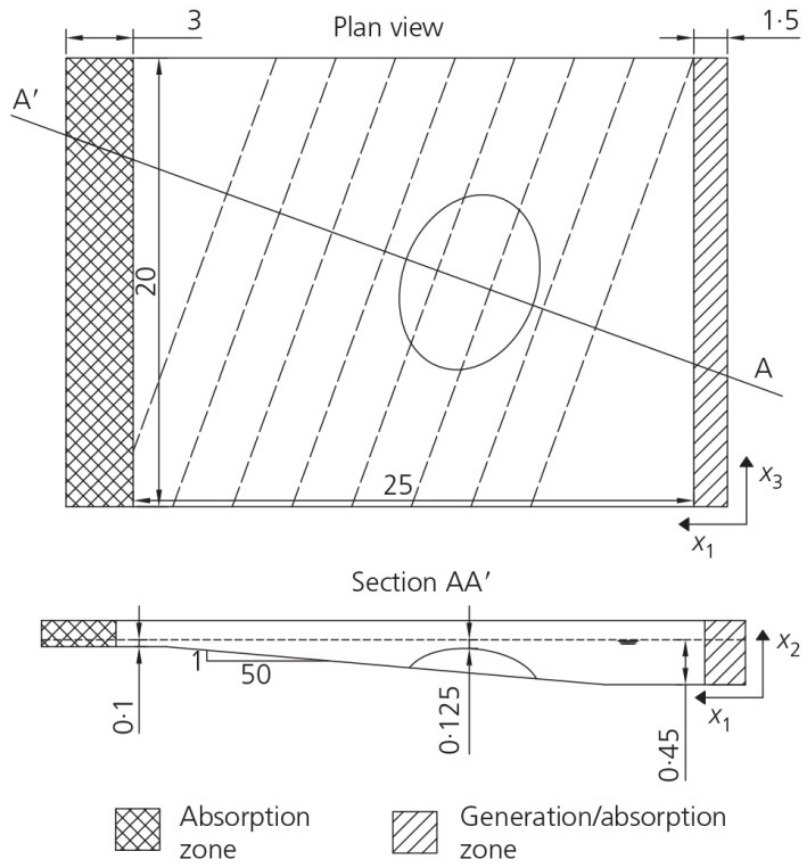

Figure 3 Elliptical shoal mounted on a constant slope (Berkhoff, 1982), with generation and absorption zones, plan view (top) and longitudinal section (bottom). All dimensions are in $\mathrm{m}$

The wave height along two cross-sections ( $a a^{\prime}$ and bb' in Figure 4(a)) is compared with experimental measurements and a mild-slope equation model (Panchang et al., 1991) in Figure 4(b). It is observed that the present model compares very well with both experimental data and the mild-slope equation model of Panchang et al. (1991). The relative differences are calculated according to Equation 12 , and it is $2 \%$ at section aa' and $4 \%$ at section bb', whereas for Panchang et al. (1991) the relative differences are $2 \%$ and $5 \%$, respectively. 


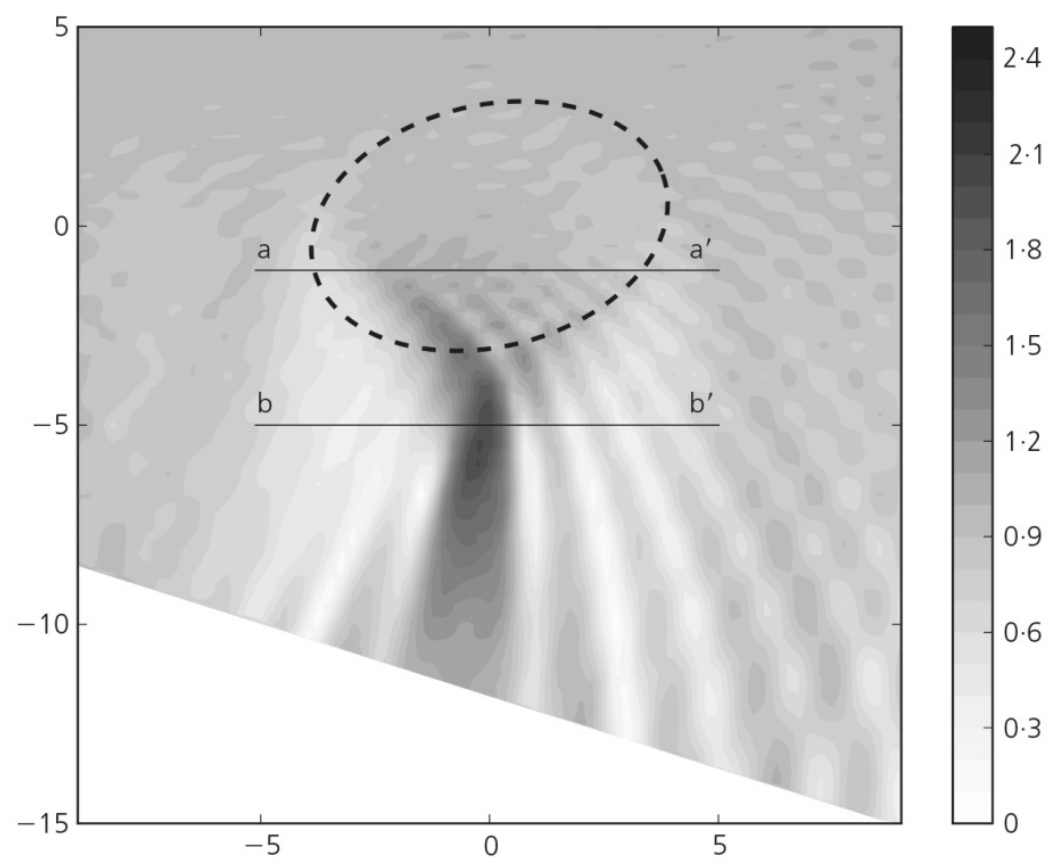

(a)
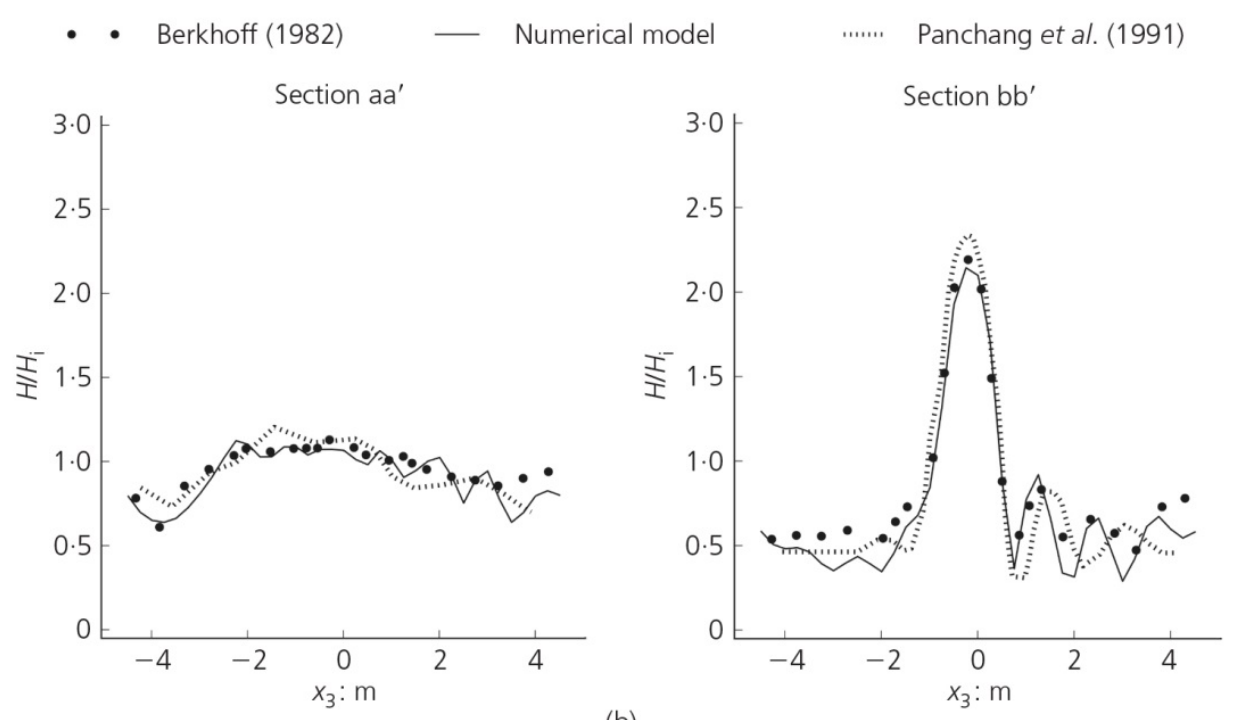

(b)

Figure 4 a) Wave height map behind the shoal. (b) Wave height distribution at sections aa' and bb', as shown in part (a). Circular symbols correspond to experimental data, solid lines to the numerical model output and dotted lines to Panchang et al. (1991)

\section{Tsunami run-up}

In this section, the numerical model is used to simulate the processes associated with tsunami propagation and run-up. The first case corresponds to the propagation, transformation and run-up of a solitary wave at a constant-slope beach (Synolakis, 1986). The second case corresponds to the study of solitary wave run-up 
at a conical island bathymetry (Briggs et al., 1995). The third case corresponds to a real-case scenario: the study of run-up at the shoreline of Monai valley, at Okushiri island, during the Hokkaido-Nansei-Oki tsunami of 1993 (Liu et al., 2008).

\subsection{Solitary wave run-up at a simple beach}

In this section, the solitary wave shoaling, breaking and run-up on a 2D, constant-slope beach $(\tan \beta=1 / 19.85)$ is modelled. Two conditions are modelled that correspond to a non-breaking $(H / d=0.0185)$ and a breaking $(H / d=0.3)$ solitary wave. An analytical solution exists for the first condition, while experimental data are available for both (Synolakis, 1986).

The operative length of the numerical wave flume is $34.85 \mathrm{~m}$ and the water depth is $1 \mathrm{~m}$. A $5 \mathrm{~m}$ long generation/absorption zone with a flat bottom is introduced at the beginning of the domain that extends the numerical domain to a total length of $39.85 \mathrm{~m}$. The slope starts at $19.85 \mathrm{~m}$ from the initial shoreline and extends $10 \mathrm{~m}$ further shoreward.

The free-slip wall condition is used at the bottom (Equations 6- 8) and the flow in the atmosphere boundary is governed by Equations 9-11. The two solitary wave conditions are generated by using first-order theory and the domain is initialised with the crest of the solitary wave located $24.85 \mathrm{~m}$ away from the initial shoreline position. At the second condition, the LES method is used for modelling wave breaking. While LES is not strictly applicable in 2D flow simulations, it has been successfully used to predict wave breaking in 2D numerical flumes (Dimakopoulos and Dimas, 2008; Hieu et al., 2006). In this case, the turbulent momentum transfer is modelled with a Smagorinsky SGS model (Smagorinsky, 1963) with coefficient Cs $1 / 40.094$ (Deardorff, 1970).

A structured mesh is generated, with constant characteristic cell size in the direction of the propagation $\left(\Delta \mathrm{x}_{1}=0.025 \mathrm{~m}\right)$. In the vertical direction, the number of cells in the vertical is constant with $\Delta \mathrm{x}_{2}$ linearly varying from $0.025 \mathrm{~m}$ at the generation zone to $0.003 \mathrm{~m}$ at the end of the slope. The size of the mesh is about 180000 cells. The non-breaking $(H / d=0.0185)$ and breaking $(H / d=0.3)$ cases were run for $30 \mathrm{~s}$ and $10 \mathrm{~s}$ of model time, respectively. Both cases need about $2 \mathrm{~h}$ to complete on $12 \mathrm{CPU}$ cores.

A sequence of snapshots of the free-surface elevation for the first condition $(H / d=0.0185)$ is presented in Figure 5, showing the shoaling, run-up and run-down of the solitary wave. The free surface profiles are compared with experimental data and the analytical solution from Synolakis (1986). The comparison reveals a good agreement between the numerical results and both the experimental data and the analytical solution. In instances where the experimental data and the analytical solution differ, the two-phase flow numerical model matches the former better. A similar sequence of snapshots is presented in Figure 6, showing the free-surface evolution of the solitary wave with $\mathrm{H} / \mathrm{d}=0.3$. The comparison with the experimental data shows that the numerical model captures well the dynamics of shoaling, breaking and run-up.

\subsection{Solitary wave run-up at a conical island}

The well-known experimental study of solitary wave run-up at a conical island, performed in Briggs et al. (1995), is numerically reproduced. The geometry of the physical model is numerically represented as shown in Figure 7. The island is a frustum of a cone, with base diameter $7.2 \mathrm{~m}$, height $0.625 \mathrm{~m}$ and beach slope of $1 / 4$, mounted on a flat bathymetry. The solitary wave propagates over the bathymetry, until it strikes the island, which is located at the centre of the basin. The flow field is expected to be symmetric with respect to the plane $A A^{\prime}$, therefore only the half domain is modelled, as shown in Figure 7. 
The operative length of the domain is $25.3 \mathrm{~m}$ and the half-width is $13.6 \mathrm{~m}$. The length of the generation/absorption zone is $4 \mathrm{~m}$ and the water depth is $0.32 \mathrm{~m}$. The fixed walls at the domain are modelled as free-slip walls (bottom, island, outlet and side wall opposite to $A A^{\prime}$ ), according to Equations $6-8$. The flow entering and exiting through the atmosphere boundary is governed by Equations 9-11. A symmetric flow condition is imposed at the plane $A A^{\prime}$ (Figure 7).
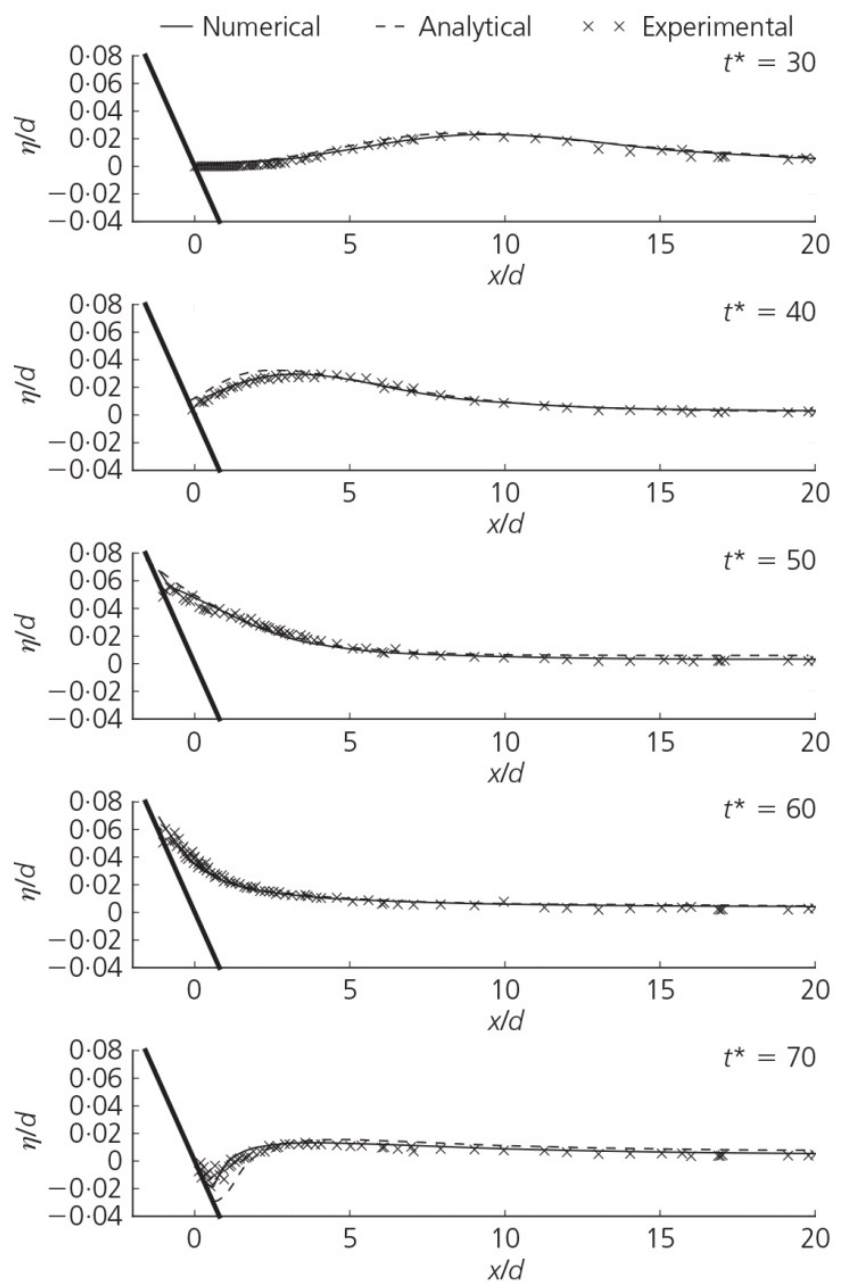

Figure 5 Free-surface elevation snapshots of a non-breaking solitary wave $(H=d 1 / 40.0185)$ running up at a constant slope beach, for consecutive time instants $(t *=t \sqrt{\boldsymbol{g} / d})$. Solid line corresponds to numerical model results, whereas dashed lines and cross symbols correspond to analytical predictions and measurements by Synolakis (1986) 

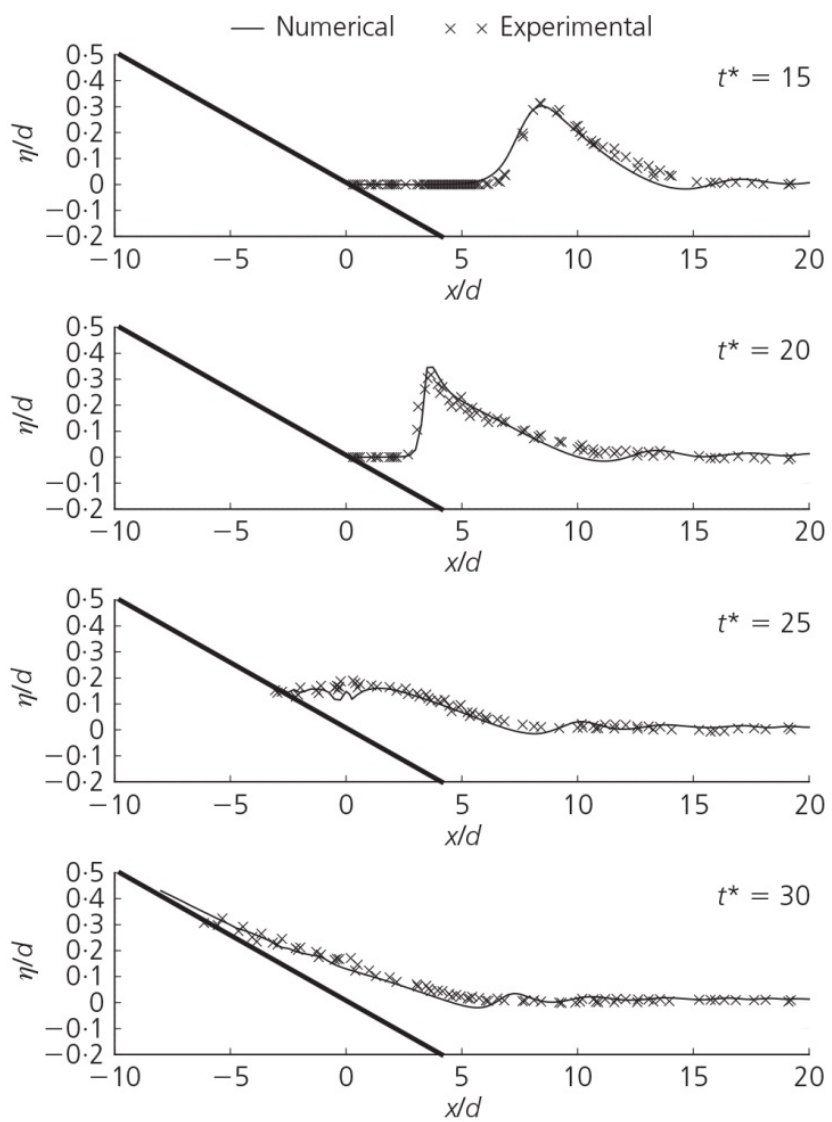

Figure 6 Free-surface elevation snapshots of a breaking solitary wave $(H / d=0.3)$ running up at a constant slope beach, for consecutive time instants $(t *=t \sqrt{\boldsymbol{g} / d})$. Solid line corresponds to numerical model results and symbols correspond to measurements from Synolakis (1986) 


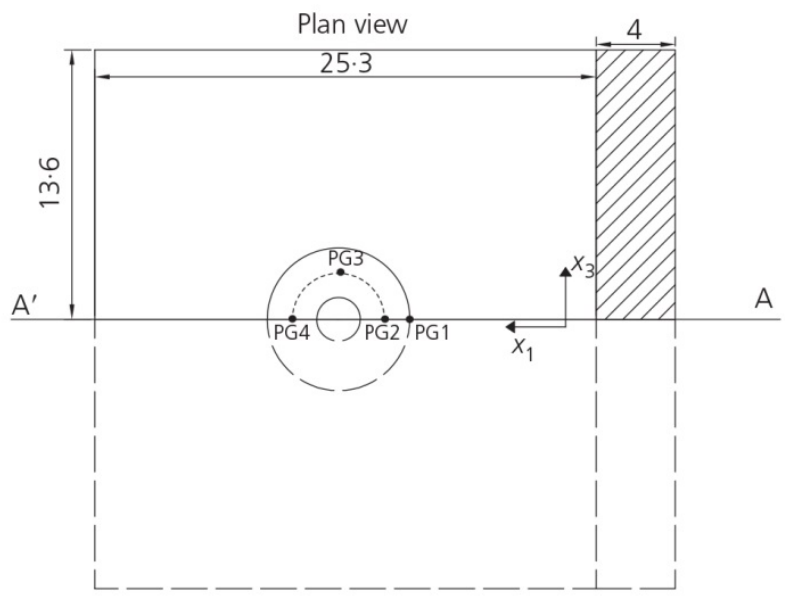

(a)

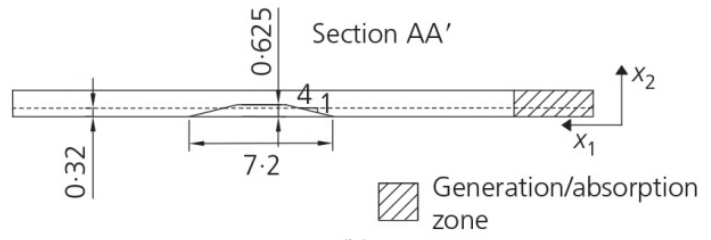

(b)

Figure 7 Conical island bathymetry (Briggs et al., 1995), with generation and absorption zones: (a) plan view and (b) longitudinal section. The locations of wave probes PG1 to PG4 are also shown. All dimensions are in $\mathrm{m}$

The tsunami is approximated by a first-order solitary wave, with height $\mathrm{H}=0.058 \mathrm{~m}$ and height-to-depth ratio $\mathrm{H} / \mathrm{d}=0.181$. A turbulence modelling approach based on the LES method is applied as in Section 4.1. Again, the LES method is not strictly compatible with the symmetry plane condition, as the condition does not represent a fully 3D flow; however, as discussed in Section 4.1, 2D SGS stress models produce good predictions for breaking waves in 2D flow conditions.

An unstructured mesh is generated, with characteristic horizontal cell sizes $\Delta \mathrm{x}_{1}=\Delta \mathrm{x}_{3}=0.04 \mathrm{~m}$ parallel and normal to the propagation direction, respectively. In the vertical direction, $\Delta \mathrm{x}_{2}$ is smaller $(0.005 \mathrm{~m})$ within an area extending up to $0.06 \mathrm{~m}$ from the still water level and more relaxed $(0.04 \mathrm{~m})$ outside. The size of the mesh is about 6 million cells. The simulation needs about a day to run for $17 \mathrm{~s}$ of model time, in parallel execution (12 CPU cores, $2.6 \mathrm{GHz}$ ). This experiment was also numerically reproduced with a Boussinesq model (Chen et al., 2000) and a shallow water equation model (Titov and Synolakis, 1998) and another OpenFOAM ${ }^{\circledR}$-based model (Higuera et al., 2013), but the latter considered a different modelling set-up (active absorbing numerical wave maker, no-slip walls, $\mathrm{k}-\epsilon$ and $\mathrm{k}-\omega$ models for turbulence).

Experimental measurements of the free-surface elevation are available at locations indicated in Figure 7 (PG1-PG4). Four wave probes are placed at corresponding locations within the computational domain and the comparison between physical and numerical model results is shown in Figure 8 . The results are also compared with the numerical models mentioned above.

The present model captures very well the shape and the amplitude of the wave, at each probe location. There is a slight delay in the arrival of the wave, suggesting some dispersion errors. The model performs better than depth-integrated models (Chen et al., 2000; Titov and Synolakis, 1998), especially at the back of 
the island (PG4), where the prediction of the wave evolution is a demanding task. Comparison with a 3D model (Higuera et al., 2013) also shows that the present modelling approach is more efficient for capturing the evolution of the free surface at the back of the island (probe PG4).

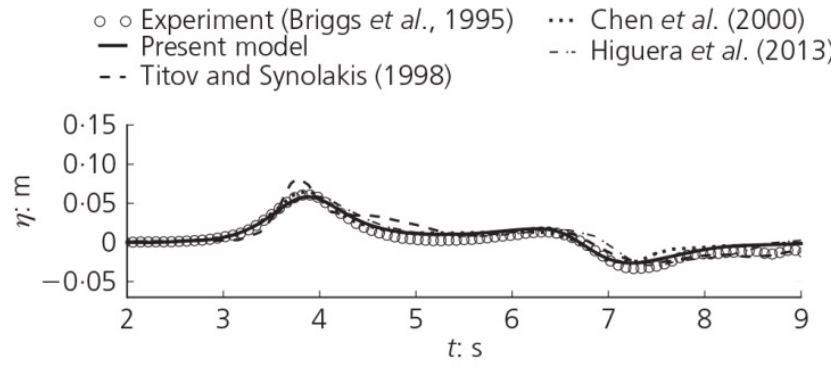

(a)

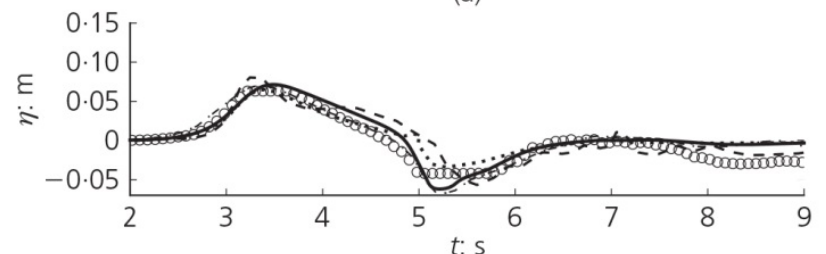

(b)

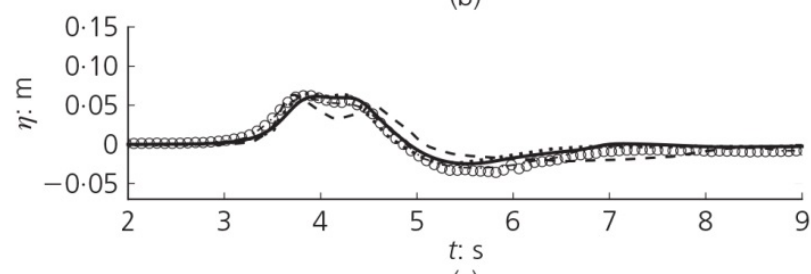

(c)

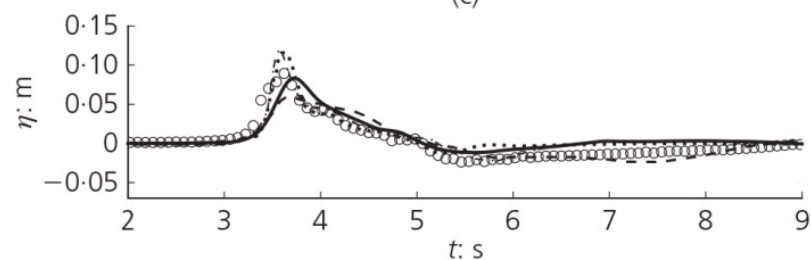

(d)

Figure 8 Surface elevation evolution at (a) PG1; (b) PG2; (c) PG3; (d) PG4. The solid line corresponds to the present numerical model, dashed, dotted and dotdashed line to Titov and Synolakis (1998), Chen et al. (2000) and Higuera et al. (2013), respectively, while circles correspond to experimental data from Briggs et al. (1995). All time series are synchronised at PG1

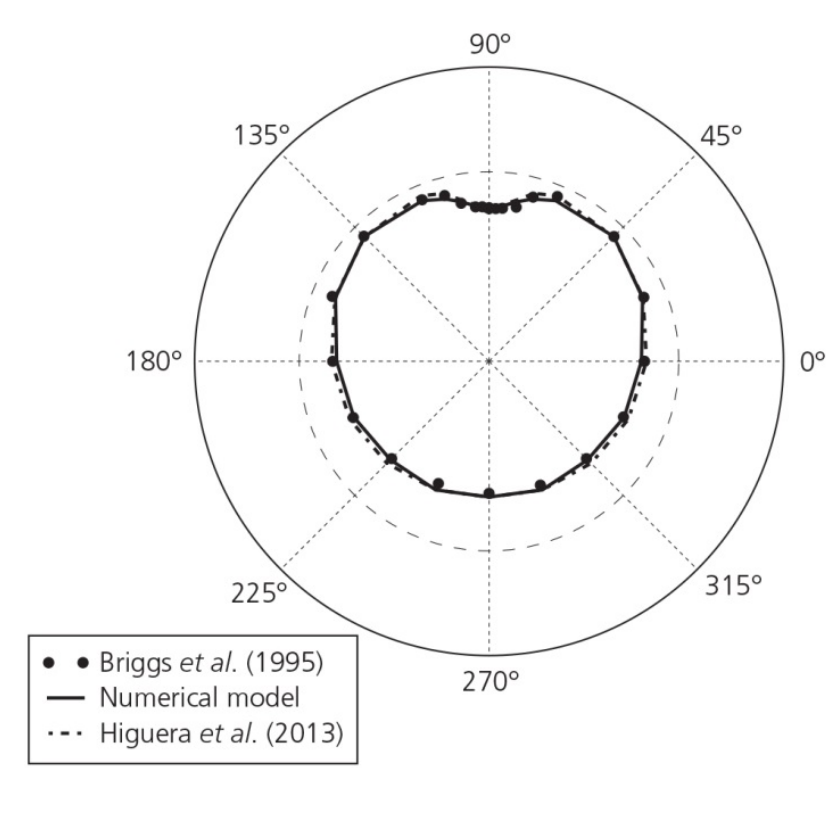

Figure 9 Maximum wave run-up chart at the perimeter of the conical island. The thin dashed line corresponds to the still water level. Circles correspond to the experimental data, solid line to the present numerical model and dot-dashed line corresponds to results from Higuera et al. (2013)

The measurement of wave run-up at a conical island is achieved with a data acquisition set-up that corresponds to the experimental configuration. An array of 24 inclined wave probes is placed at the perimeter of the island. The array is more densely arranged at the lee side of the island to increase the measurement resolution, as the refraction of the solitary wave creates a sharp run-up pattern at the shoreline. For defining maximum run-up, mesh cells at the shoreline are considered completely inundated when a . 0.1 (10\% water). 
The maximum wave run-up predicted from the numerical model is shown in Figure 9, in comparison with experimental data and results from Higuera et al. (2013). The comparison reveals very good agreement between the physical and the present numerical model, with the latter having less than $10 \%$ average difference in run-up predictions from the physical model. Run-up predictions from Higuera et al. (2013) show a very similar trend with the present numerical model.

\subsection{Tsunami run-up at Monai valley}

The physical model of this case was constructed in a $205 \mathrm{~m}$ long, $6 \mathrm{~m}$ deep and $3.5 \mathrm{~m}$ wide flume, in 1/400 scale (Liu et al., 2008). A 3D view of the Monai valley bathymetry is shown in Figure 10. The bathymetry is relatively steep and there is an island in front of the shore that rises about $20 \mathrm{~m}$ above the sea level $(0.05 \mathrm{~m}$ in model scale). Three wave probes are placed at the positions shown in Figure 10 (gauges 1, 2 and 3), to measure the tsunami run-up, as it strikes the shoreline.

The numerical model is configured to represent the physical model and not the real bathymetry, thus all dimensions are in model scale. The length and the width of the bathymetry domain are $5.5 \mathrm{~m}$ and $3.4 \mathrm{~m}$, respectively. The generation/absorption zone is added by truncating the bathymetry at $0.13 \mathrm{~m}$ below the sea level and merging a flat bottom at this level.

Two configurations of the generation/absorption zone are used, with lengths $0.5 \mathrm{~m}$ and $5 \mathrm{~m}$, respectively. The longer generation/ absorption zone is used to assess the capability of the model in absorbing the reflected tsunami at the shoreline. The free-surface profile of the generated tsunami corresponds to a leading depression N-wave (LDN) and it is reproduced from the physical model (Liu et al., 2008; NOAA, 2014). This profile cannot be described by an analytical solution and it is reconstructed by a 14th-order polynomial, which approximates the actual profile with a correlation coefficient R2 $>0.99$.

Unlike the previous cases, the relaxation zone method was used to force only the free-surface elevation and not the velocities. In this case, the model by default assumes that the pressure driving the velocity field is hydrostatic and this assumption is reasonably close to reality.

The remaining boundaries are configured similarly to previous cases: Equations 9-12 govern the flow at the atmosphere boundary, while free-slip conditions are imposed at solid walls. A relatively coarse, unstructured mesh is used, having a size of bout 170000 cells in both cases. Characteristic cell sizes along and normal to wave propagation $\left(\Delta \mathrm{x}_{1}\right.$ and $\left.\Delta \mathrm{x}_{3}\right)$ are $0.05 \mathrm{~m}$. In the vertical direction, the characteristic size is $\Delta \mathrm{x}_{2}=0.005 \mathrm{~m}$ at a distance of $0.035 \mathrm{~m}$ from the still water level and $\Delta x_{2} 1 / 40.05$ outside this region. For the shorter =generation/absorption zone case, mesh refinement is the same as stated above. To maintain the same mesh size for the longer generation/absorption zone case, cell size $x 1$ is increased with a constant ratio (about 1.1) in the generation/absorption zone, as the inflow boundary is approached. The domain was initialised with a still water level. The simulation ran for $200 \mathrm{~s}$ of model time, as in the physical model, and it required $4 \mathrm{~h}$ to complete, while computing on $12 \mathrm{CPU}$ cores $(2.6 \mathrm{GHz})$.

The free-surface elevation is measured at the three locations shown in Figure 10 and is compared with experimental data in Figure 11. In this figure, two regions can be distinguished: the first ( $\mathrm{t}, 25 \mathrm{~s})$ corresponds to the propagation of the generated tsunami and the second ( $\mathrm{t} .25 \mathrm{~s})$ corresponds to the propagation of secondary waves that originate from the tsunami, as it reflects back from the upstream wall. 

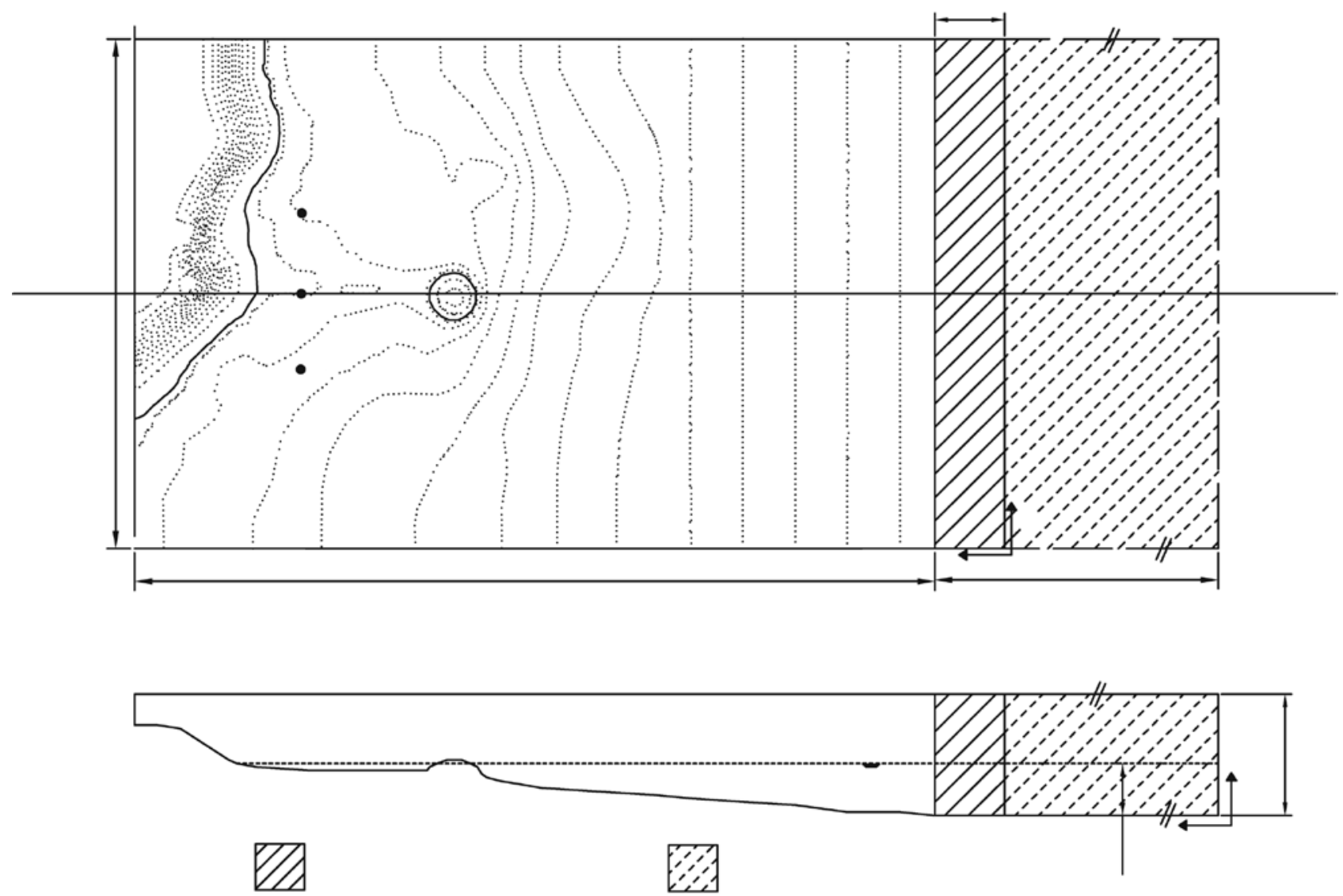

Figure 10 Figure 10. Monai valley bathymetry with $0.5 \mathrm{~m}$ long generation/absorption zone. The dashed line corresponds to the generation/absorption zone extension. Bathymetry contours correspond to $0.01 \mathrm{~m}$ increment (model scale) and the solid line contour corresponds to the initial position of the shoreline. The locations of gauges 1, 2 and 3 are also shown. All dimensions are in $\mathrm{m}$.

The first region is more important in terms of studying the tsunami impact on the shoreline. The elevation rise and the peak of the wave is preceded by a depression, which the numerical model captures as a trend at gauge 1 , but not as clearly in gauge 2 and gauge 3 . During the rise of the free-surface elevation to its peak, the numerical model responds very well: the shape of the profile is quite similar to the one measured in the lab, capturing also some secondary peaks at gauge 1 and gauge 2 , while the maximum free-surface elevation is about $5 \%$ different from the physical model. In addition, the difference between the two cases (short and long generation/absorption zone) is not significant, confirming that the relaxation zone method is robust.

In the second region, the experimental data show the secondary waves that reflect from the upstream boundary. During the duration of the test, five of these secondary waves appear (three are shown in Figure 11 ) and their amplitude is practically stable and about $30 \%$ of the maximum amplitude. In the numerical model with the shorter generation/absorption zone, there are about ten secondary waves appearing in the same duration (five shown in Figure 11), as the upstream boundary is located closer than the physical model. The secondary peak amplitude is about $20 \%$ of the maximum and it is decreasing to a very low value at the tenth secondary wave. 


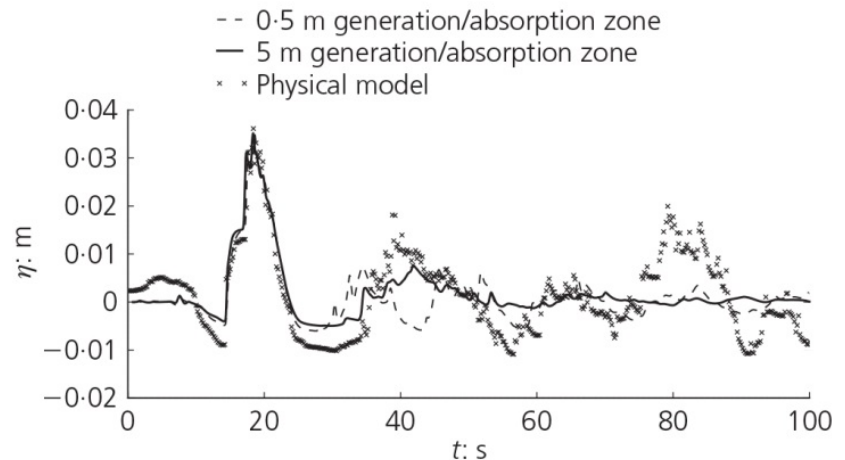

(a)

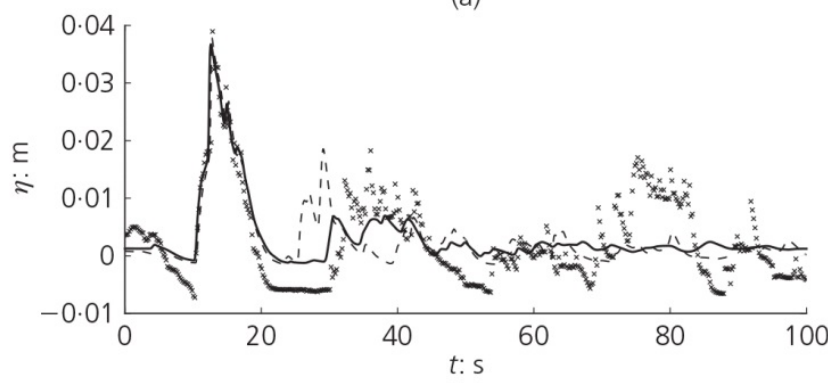

(b)

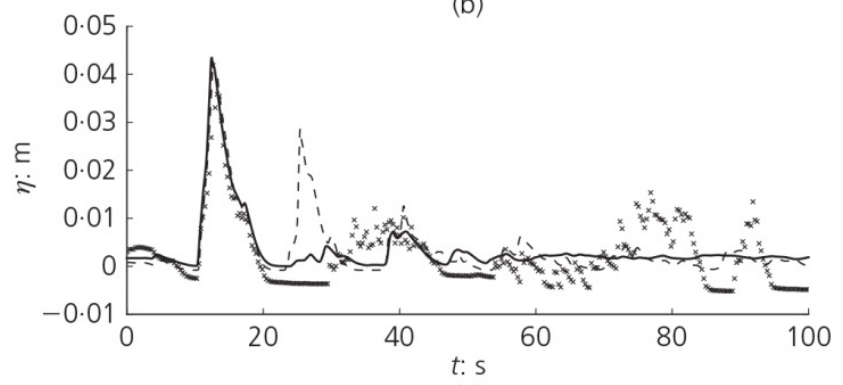

(c)

Figure 11 Free-surface elevation at (a) gauge 1; (b) gauge 2; (c) gauge 3. Dashed and solid lines correspond to the numerical model output for the shorter $(0.5 \mathrm{~m})$ and the longer $(5 \mathrm{~m})$ generation/absorption zone, respectively. Symbols correspond to experimental data from Liu et al. (2008)

For the longer generation/absorption zone case, there is one secondary peak following the tsunami, which is smoother than the previous cases and its peak is about $20 \%$ of the maximum elevation observed. There are no secondary peaks following, as they are completely dissipated in the generation/absorption zone.

To summarise the observations above, the numerical model is capable of generating a tsunami and predicting its transformation, as it impacts on the shoreline. The computational resources necessary to capture the important aspects of the flow evolution are acceptable, as the simulation can complete within reasonable time using a standard personal computer. The length of the generation/absorption zone is critical for absorbing the reflected tsunami and a longer generation/absorption zone could completely dissipate the secondary waves. This extension of the generation/absorption zone is made at no extra cost, by appropriately configuring the mesh refinement. Thus, it is possible to focus on a particular area of the shoreline and to allow more refinement on natural and man-made geometrical features close to the shoreline, without the model suffering from artificial reflection and sloshing effects. 


\section{Conclusion}

A 3D numerical model is presented, based in the OpenFOAM ${ }^{\circledR}$ CFD modelling system. The model is validated against experimental data for regular wave shoaling and refraction and for tsunami run-up.

The model captures all the important processes occurring during regular wave propagation over 3D shoals and in particular the characteristic short-crested free-surface patter caused by the wave ray intersection behind the shoal.

The study of a solitary wave run-up at a constant-slope beach and at a conical island reveals that the model is capable of simulating tsunami wave propagation, transformation and interaction with the coastline. The free-surface elevation evolution compares very well with experimental data.

Finally, a 3D simulation of a real-case scenario is performed, studying the impact of the Hokkaido-NanseiOki tsunami to the Monai valley shoreline. The model is capable of generating a tsunami from field or experimental measurements and adequately predicts its evolution over a real foreshore in a relatively short time for a 3D model (,4 $\mathrm{h}$ in $12 \mathrm{CPU}$ cores); therefore, further mesh refinement to include the modelling of interaction with structures will not be prohibitive, in terms of computational resources.

This work has been carried out at HR Wallingford within the framework of the internal research project CAY0457. The authors wish to thank Dr Stephen Richardson and Se'bastien Bourban (HRWallingford) for supporting this work and Daniele Longo for his help during the set up of the simulations.

\section{References}

Berkhoff JCW (1982) Verification Computations of with Linear Wave Propagation Models. Delft Hydraulics Laboratory, Delft, the Netherlands, report W 154-VIII.

Boussinesq J (1872) The'orie des ondes et des remous qui se propagent le long d' un canal rectangulaire horizontal, en communiquant au liquid contenu dans ce canal des vitesses sensiblement paralleil de la surface au fond. Journal de Mathe'matiques Pures et Applique'es 17(2): 55-108 (in French).

Briggs MJ, Synolakis CE, Harkins GS and Green D (1995) Laboratory experiments of tsunami run-up on a circular island. Pure Applied Geophysics 144(3-4): 569-593.

Chen Q, Kirby JT, Dalrymple RA, Kennedy AB and Chawla A (2000) Boussinesq modelling of wave transformation breaking and runup. II: 2D. Journal of Waterway, Port, Coastal and Ocean Engineering 126(1): 48-56.

Christensen ED (2006) Large eddy simulation of spilling and plunging breakers. Coastal Engineering 50(4): 181-198.

Deardorff J (1970) A numerical study of three-dimensional turbulent channel flow at large Reynolds numbers. Journal of Fluid Mechanics 41(2): 453-480.

Dimakopoulos AS and Dimas AA (2008) Large-wave simulation of spilling breakers over constant-slope bottom. Proceedings of 27th International Conference on Offshore Mechanics and Arctic Engineering, Estoril, Portugal, OMAE2008-57164, pp. 1-8.

Galland JC, Coutal N and Hervouet JM (1991) TELEMAC: a new numerical model for solving shallow water equations. Advances in Water Resources 14(3): 138-148. 
Hieu PD, Tanimoto K and Ca VT (2006) Numerical simulation of breaking waves using a two-phase flow model. Applied Mathematical Modelling 28(11): 983-1005.

Higuera P, Lara JL and Losada IJ (2013) Simulating coastal engineering processes with OpenFOAM ${ }^{\circledR}$ : Coastal Engineering 71(1): 118-134.

Hirt CW and Nichols BD (1981) Volume of fluid (VOF) method for the dynamics of free boundaries. Journal of Computational Physics 39(1): 201-225.

HR Wallingford (2013) Numerical Wave and Current Facility. HR Wallingford, Wallingford, Oxfordshire, UK, technical report CAY0457-RT002.

Hsiao SC and Lin TC (2010) Tsunami-like solitary waves impinging and overtopping an impermeable seawall: Experiment and RANS modelling. Coastal Engineering 57(1): 1-18.

Ito $Y$ and Tanimoto K (1972) A method of numerical analysis of wave propagation - Application to wave diffraction and refraction. Proceedings of the 13th Coastal Engineering Conference, Vancouver, British Columbia, Canada. American Society of Civil Engineers, Reston, VA, USA, vol. 1, pp. 503-522.

Jacobsen NG, Fuhrman DR and Fredsøe J (2012) A wave generation toolbox for the open-source CFD library: OpenFOAM ${ }^{\circledR}$. International Journal of Numerical Methods in Fluids 70(9): 1073-1088.

Jasak H (1996) Error Analysis and Estimation for the Finite Volume Method with Applications to Fluid Flows. PhD thesis, Imperial College, London, UK.

Liu PLF, Yeh H and Synolakis CE (2008) Benchmark Problems in Advanced Numerical Models for Simulating Tsunami Waves and Run-up. World Scientific, Singapore.

Mayer S, Garapon A and Sorensen L (1998) A fractional step method for unsteady free-surface flow with applications to non-linear wave dynamics. International Journal for Numerical Methods in Fluids 28(2): 293-315.

NOAA (National Oceanic and Atmospheric Administration, Center for Tsunami Research) (2014) Tsunami Runup onto a Complex Three-dimensional Beach. NOAA Center for Tsunami Research, Monai Valley, Seattle, WA, USA. See http://nctr.pmel.noaa.gov/benchmark/Laboratory/Laboratory MonaiValley/index.html (accessed 19/09/2013).

OpenFOAM ${ }^{\circledR}$ Foundation (2013) OpenFOAM ${ }^{\circledR}$ User Guide. See http://www.openfoam.org/docs/user/ (accessed 19/09/2013).

Panchang VG, Wei G and Benoit CR (1991) Solution of the mildslope wave problem by iteration. Applied Ocean Research 13(4): 187-199.

Pope SB (2000) Turbulent Flows. Cambridge University Press, Cambridge, UK.

Rusche H (2002) Computational Fluid Dynamics of Dispersed Two-phase Flows at High Phase Fractions. $\mathrm{PhD}$ thesis, Imperial College, London, UK.

Saint Venant A (1871) Theorie du mouvement non permanent des eaux, avec application aux crues des rivieres et a l'introduction de marees dans leurs lits. Comptes Rendus des Seances de l'Academie des Sciences 73(4): 147-154, 247-350 (in French).

Smagorinsky J (1963) General circulation experiments with the primitive equations. Monthly Weather Review 91(3): 99-164. 
Synolakis CE (1986) The Runup of Long Waves. PhD thesis, California Institute of Technology, Pasadena, CA, USA.

Titov VV and Synolakis CE (1998) Numerical modelling of tidal wave runup. Journal of Waterway, Port, Coastal and Ocean Engineering 124(4): 157-171.

Watanabe Y, Saeki H and Hosking RJ (2005) Three-dimensional vortex structure under breaking waves. Journal of Fluid Mechanics 545(12): 291-328.

Wei G and Kirby JT (1995) A time-dependent numerical code for extended Boussinesq equations. Journal of Waterway, Port, Coastal and Ocean Engineering 120(5): 251 